\title{
Ethically Researching Local Impacts of Environmental Change without Travel
}

\author{
Ilan Kelman 1,2,3 (D) \\ 1 Institute for Risk \& Disaster Reduction, University College London, London WC1E 6BT, UK; \\ ilan_kelman@hotmail.com \\ 2 Institute for Global Health, University College London, London WC1E 6BT, UK \\ 3 University of Agder, 4630 Kristiansand, Norway
}

\begin{abstract}
Responses to the COVID-19 pandemic, which began in 2020, included local and international travel restrictions alongside limits on face-to-face gatherings. These measures impinged on participatory research examining local impacts of environmental change. In response, many researchers adopted techniques that could be implemented without travel. This article explores some of the consequent research ethics issues.
\end{abstract}

Keywords: ethics; fieldwork; methods; methodology; participatory action research; participatory research

\section{Introduction}

The world is undergoing multiple modes and scales of environmental change, as it

Citation: Kelman, I. Ethically Researching Local Impacts of Environmental Change without Travel. Geosciences 2021, 11, 316. https://doi.org/10.3390/ geosciences 11080316

Academic Editors: Piero Farabollini, Francesco Muto, Francesca

Romana Lugeri, Francesco De Pascale and Jesus Martinez-Frias

Received: 8 July 2021

Accepted: 26 July 2021

Published: 27 July 2021

Publisher's Note: MDPI stays neutral with regard to jurisdictional claims in published maps and institutional affiliations. human activities on these changes and the speed of this human influence. Focused local action can often not control or impact global trends, instead being forced to deal with the impacts. Successful action can thus be based on the local contexts, so understanding them requires a variety of knowledges, disciplines, methods, data types, and analysis approaches.

For doing so, one suite of research methods is involving the people affected and acting in the scientific process, labelled with terms including "participatory action research" and "participatory processes" [2-4]. Concatenating various sources, e.g., [2-4], participatory research, is broadly defined as enacting science with the people being researched, that is, defining, developing, producing, and implementing the research process together with the populations who are being studied. The purposes of participatory research including avoiding the exploitation of people under study, improving the science's robustness and relevance, and enhancing usefulness for and useability by people aiming to help themselves with evidence-based action. Participatory research has typically been implemented inperson, although the advent of real-time internet-based video communication has led to the techniques being conducted without people being in the same room [5].

As the COVID-19 pandemic gripped the world in 2020, responses included local and international travel restrictions alongside limits on face-to-face gatherings. Neither environmental changes nor research into local action stopped. Instead, remote participatory research accelerated [6]. The aim of this paper is to explore some aspects of the ethical considerations emerging when researching local impacts of environmental changes without travel, namely through participatory research. The next section collates some perspectives from people's published experience, and then the conclusions summarize the ideas.

\section{Perspectives of Participatory Research without Travel}

Many examples of participatory research methods can be completed online, including interviews and focus groups of all types (e.g., structured, semi-structured, and unstructured), tick-box surveys, participatory mapping exercises (e.g., resource maps, dream maps, futures maps, and change maps), and ranking of dreams, issues, and concerns. Subject 
to the availability of technology and a comfortable environment at home, participants do not need to go to other sites to be part of the research. Participatory research techniques requiring activities outside of one's home can also be conducted remotely, provided that it is safe to do so, and that the technology is available. For instance, aspects of PhotoVoice [7] and location walk-throughs [8] can be completed by individuals on their own, in their own way or after training, or in real-time with a remote researcher, provided that the participants have a good roaming internet or phone connection and a suitable device for staying connected.

Ethical and impact advantages and disadvantages emerge [6-8]. One advantage of remote work is that recording can be done without the intrusiveness of a recording device in the room. If sessions are not being recorded, then a researcher dedicated to notetaking can join the online call and be almost invisible, compared to the sounds of writing or typing when a notetaker is in the same room as the interview or mapping exercise. For methods requiring moving around a place, not having an on-site researcher might provide the participants with more freedom or the assumption of such, making themselves more aware of the data and, hence, how to have research impact for themselves, although the implementation of the method might vary more among participants.

The baseline is that all research methods have impact and ethical advantages and disadvantages [9]. In analyzing, interpreting, and writing up concepts and data, these advantages and disadvantages need to be admitted explicitly, with indications of how they might or might not affect the participants. It is not that online participatory processes are necessarily better or worse than face-to-face activities. They are different, meaning that analyzing those differences and the consequences would be part of the research process. There is no change from understanding positionality (positionalities) and reflexivity (reflexivities), in which the researchers' and participants characteristics, interests, and viewpoints might influence each other's interactions and responses and, hence, the data [10]. Understanding and tackling implicit bias and unconscious bias [11] can improve research ethics by contributing to overcoming any positionality-related concerns. Exploration into, and training for identifying, differences and similarities in online and face-to-face participatory processes-advantageous and disadvantageous-would assist in overcoming concerns related to any methodological approach.

High ethical standards and pathways to impact would be needed for research on-site and/or face-to-face. Aside from the resources and time required for travel, a danger exists of compressing or curtailing research in order to fit within a budget or a fixed timeline due to travel tickets purchased. In-person research can be constrained by local transportation options [12] and personal safety concerns [13]. For impact, post-travel remote contact with the research location assists anyway. Online research can be more logistically straightforward than travelling, with major difficulties being time zone differences, technological reliability, and technological security. Equity also plays an ethical role in balancing different research modes and participants [14]. Many locations have no capability for remote work, so being in the location is essential. Conversely, generating research budgets to spend time in any place is not always possible. Internet-based participatory processes can open up locations that have the technology but where travel is not easy or affordable.

Additionally, many researchers successfully research their own homes, meaning that on-site and face-to-face data can be collected without the extensive travel or moral difficulties that come from appearing to be an outsider. Conversely, being a researcher in one's own home brings its own ethics and impact challenges $[15,16]$. The researcher might end up being an elite within their own place while having the potential for being ostracized by critiquing it or seeking to apply research findings. Being a complete outsider conducting FIFO (fly in, fly out) research has advantages and might support marginalized people in publicizing their situations beyond the power structures in which they are trapped. Remote research can support less-heard voices further if participants can conduct their activities privately (as much as possible) without the presence of an outsider drawing attention to who is participating and without using a public venue that could be monitored. 
Such advantages of remote research are not new, since research has often been completed without the researcher travelling. Interviews have been done by telephone [17], surveys have been done by correspondence [18], local participatory processes have been done by training locals remotely or in-person away from their home [19], and teleresearch is about research through online searching [20].

Nonetheless, the data, ethical robustness, and impact of remote participatory processes could be challenged. Without face-to-face collaboration between outsiders and locals, a researcher can miss cues that are used in interaction, might generate less trust in cultures that favor "eyeball-to-eyeball" interactions [21], and cannot always contextualize what people say with the researcher's own experiences of and responses to being in a location. Digital data are hackable, whether stored online or offline, similarly to any paper records or non-digital recordings being open to theft or misplacement.

Online participatory research, though, cannot collect all needed data. Irrespective of advances in data collected by satellites and aircraft, some environmental data collection requires an on-site presence even for using drones. Many archives are not digitized or are merely time series listed in paper bundles on someone's dusty shelves. An outsider can be a positive catalyst, bringing people together in a common space, giving presentations at local centers or homes, organizing information and data that locals did not consider to be important, or giving constructive voice to populations with less power. Certainly, the difference between insider and outsider researchers is not necessarily clearly delineated [22]. One suitable method deliberately seeking to blur insiders and outsiders is deep hanging out [23], yielding improved research-related impact by researchers getting involved locally, shadowing day-to-day work, actively participating in activities and daily life, engaging in informal chats, making friends, and supporting locals in what they request, which could be picking up litter on beaches, cleaning factories, or providing services such as professional healthcare. However, volunteerism as a research method leads to its own ethical dilemmas [24].

When seeking positive research impact, an immersive experience can create and shed as many research biases as not having an immersive experience. Researcher-participant interaction has been demonstrated to introduce biases in the data [25], raising moral questions about the extent to which this should happen, although similar biases can be evident online as well. Again, any research method gains and loses some ethical aspects. The key is being open regarding the gains and losses, especially regarding their possible influence on the data and interpretation.

Another ethical note regarding any participatory research is returning results to the people who were involved in order to achieve positive impact. Using people's time and resources to obtain data from them and then publishing it without their further involvement is a research ethics problem. The process becomes extractive and exploitive, returning little to the participants after the researcher has departed, even if framed otherwise [26,27]. These difficulties can arise no matter how the participatory research is conducted: remotely, in-person, or a hybrid. Actions to improve the research ethics are the same: ask the people involved what they would want from the research, and then provide it, as long as the requests do not cause further problems such as illegal activities, further moral dilemmas, or other forms of exploitation. Possibilities to provide include resources, information, publicity, intellectual support, training, products such as datasets or maps, or further collaborations. As long as actions remain within the research ethics approval-e.g., restrictions might exist on giving money, returning full interview transcripts, or publicity, which could identify participants - then researchers need to be responsive to the requests of people who were involved in the research, again without causing further problems. This is embodied in the definition and purpose of participatory research, especially for improving positive impact. 


\section{Conclusions}

This paper has examined some ethical aspects emerging for participatory research without travel for exploring local impacts of environmental changes. The quandaries, subtleties, provisos, nuances, and contextualities concatenate to indicate few straightforward lessons. Being on-site can still yield distance between researchers and others while being physically distant does not necessarily mean being personally remote. Being closer socially despite physical distance might challenge stereotypical notions of so-called "fieldwork" (a term which itself can be pejorative) that are engrained in many disciplines. Irrespective, ethics must still be fully adhered to, covering institutional and legal research ethics procedures while treating everyone respectfully, understanding biases, and working through power relations. Ethically researching local impacts of environmental change can be done without travel, ensuring that all the advantages of remote research are used while overcoming all the disadvantages—exactly as it would be with on-site research.

Funding: This research was supported through the Belmont Forum by the UK's Natural Environment Research Council (NERC) [grant number NE/T013656/1].

Conflicts of Interest: The author declare no conflict of interest.

\section{References}

1. IPCC. Fifth Assessment Report; Intergovernmental Panel on Climate Change (IPCC): Geneva, Switzerland, 2013.

2. Cadag, J.R.D.; Gaillard, J.C. Integrating Knowledge and Actions in Disaster Risk Reduction: The Contribution of Participatory Mapping. Area 2012, 44, 100-109. [CrossRef]

3. Chambers, R. Participatory Workshops: A Sourcebook of 21 Sets of Ideas and Activities; Routledge: London, UK, 2002.

4. Kindon, S.; Pain, R.; Kesby, M. Participatory Action Research Approaches and Methods: Connecting People, Participation and Place; Routledge: Abingdon, UK, 2007.

5. Nehls, K.; Smith, B.D.; Schneider, H.A. Video-Conferencing Interviews in Qualitative Research. In Enhancing Qualitative and Mixed Methods Research with Technology; Hai-Jew, S., Ed.; IGI Global: Hershey, PA, USA, 2014; pp. 140-157.

6. Hall, J.; Gaved, M.; Sargent, J. Participatory Research Approaches in Times of Covid-19: A Narrative Literature Review. Int. J. Qual. Methods 2021, 20,1-15. [CrossRef]

7. Liegghio, M.; Caragata, L. COVID-19 and Youth Living in Poverty: The Ethical Considerations of Moving From In-Person Interviews to a Photovoice Using Remote Methods. Affilia 2021, 36, 149-155. [CrossRef]

8. Parks, M.; Roesch-McNally, G. Bridging scientific and experiential knowledges via participatory climate adaptation research: A case study of dry farmers in Oregon. J. Agric. Food Syst. Community Dev. 2021, 10, 187-203.

9. Martin, B. The Bias of Science; Society for Social Responsibility in Science: Canberra, Australia, 1979.

10. England, K.V.L. Getting Personal: Reflexivity, Positionality, and Feminist Research. Prof. Geogr. 1994, 46, 80-89. [CrossRef]

11. Agarwal, P. Unravelling Unconscious Bias; Bloomsbury: London, UK, 2020.

12. Bell, K. Doing qualitative fieldwork in Cuba: Social research in politically sensitive locations. Int. J. Soc. Res. Methodol. 2013, 16, 109-124. [CrossRef]

13. Peritore, N.P. Reflections on dangerous fieldwork. Am. Soc. 1990, 21, 359-372. [CrossRef]

14. Leresche, E.; Truppa, C.; Martin, C.; Marnicio, A.; Rossi, R.; Zmeter, C.; Harb, H.; Hamadeh, R.S.; Leaning, J. Conducting operational research in humanitarian settings: Is there a shared path for humanitarians, national public health authorities and academics? Conf. Health 2020, 14. [CrossRef] [PubMed]

15. Feng, Y.; Jament, J. International research students' emotional experiences in researching education in their home contexts. Int. J. Work Org. Emot. 2011, 4, 361-369. [CrossRef]

16. Vernooij, E. Navigating multipositionality in 'insider' ethnography. Med. Anthro. Theory 2017, 4. [CrossRef]

17. Colombotos, J. Personal versus telephone interviews: Effect on responses. Public Health Rep. 1969, 84, 773-782. [CrossRef] [PubMed]

18. Scott, C. Research on Mail Surveys. J. Royal Stat. Soc. 1961, 124, 143-195. [CrossRef]

19. Anderson, S. Linking Flexible Delivery and Community Development: The Wugularr Story; NCVER: Canberra, Australia, 2009.

20. Harris, J. Education Teleresearch: A Means, Not an End. Learn. Lead. Technol. 1998, 26, 42-48.

21. Magee, A.D.; Verdon-Kidd, D.C.; Kiem, A.S.; Royle, S.A. Tropical cyclone perceptions, impacts and adaptation in the Southwest Pacific: An urban perspective from Fiji, Vanuatu and Tonga. Nat. Hazards Earth Syst. Sci. 2016, 16, 1091-1105. [CrossRef]

22. Dwyer, S.C.; Buckle, J. The Space Between: On Being an Insider-Outsider in Qualitative Research. Int. J. Qual. Methods 2009, 8, 54-63. [CrossRef]

23. Clifford, J. Anthropology and/as Travel. Etnofoor 1996, 9, 5-15.

24. Goerisch, D. “Doing Good Work": Feminist Dilemmas of Volunteering in the Field. Prof. Geogr. 2017, 69, 307-313. [CrossRef] 
25. Miyazaki, A.D.; Taylor, K.A. Researcher Interaction Biases and Business Ethics Research: Respondent Reactions to Researcher Characteristics. J. Bus. Ethics 2009, 81, 779-795. [CrossRef]

26. Ladwig, J.G. Is Collaborative Research Exploitative? Educ. Theory 1991, 41, 111-120. [CrossRef]

27. Millum, J. Sharing the benefits of research fairly: Two approaches. J. Med. Ethics 2012, 38, 219-223. [CrossRef] [PubMed] 